\title{
DA ERUDIÇÃO BIZANTINA - UM ENSAIO
}

\author{
Naiara Krachenski*
}

Resumo: Neste artigo, procuramos demarcar algumas condições culturais intrínsecas ao Império Bizantino e outras externas a ele que proporcionaram o desenvolvimento de uma sociedade cuja tradição erudita preservou e perpassou a cultura filosófica da Grécia Clássica. Detemo-nos em especial na obra De Administrando Imperio escrita pelo Imperador Constantino VII Porfirogênito, que governou o Império Romano do Oriente de 945 a 959 d.C. Nesta obra dedicada a seu filho, o basileu sublinha a importância de uma educação erudita àquele que deseja tornar-se seu sucessor.

Palavras-Chave: Império Bizantino; Erudição Bizantina; Constantino VII Porfirogênito.

Resumen: Hemos tratado de delimitar algunas condiciones culturales intrínsecas al Imperio Bizantino y ajena a lo que condujo al desarrollo de una sociedad cuya tradición académica ha conservado y pasó adelante la cultura filosófica de la Grecia clásica. Hagamos una pausa, en particular, en la obra De Administrando Imperio escrita por el emperador Constantino VII Porphirogenito, que gobernó el Imperio Romano de Oriente desde 945 hasta 959 d.C. En este libro dedicado a su hijo, el emperador subraya la importancia de una educación clásica para quien desea convertirse en su sucesor.

Palabras-Clave: Imperio Bizantino; Erudición Bizantina; Constantino VII Porphirogenito

* Graduanda em História da Universidade Federal do Paraná. 


\title{
DA ERUDIÇÃO BIZANTINA - UM ENSAIO
}

\author{
Naiara Krachenski
}

"Os bizantinos habitam um território que pelo lado do mar goza da posição mais favorável que se possa imaginar, tanto para as necessidades de defesa, como para a prosperidade dos habitantes"' ${ }^{1}$ Já no século II a.C. o historiador grego Políbio narrava a privilegiada situação geográfica de Bizâncio, cidade que foi fundada no ano de 657 a.C. por um grupo de colonos proveniente da cidade grega de Mégara. Como já observava Políbio, antes mesmo de Bizâncio se tornar um poderoso império no Mediterrâneo, a cidade erguida entre o Bósforo e o mar Negro apresentava uma próspera economia e uma estratégica posição militar. Tais características foram essenciais para que, no século IV d.C., durante árduos tempos pelo qual passava o Império Romano, Constantinopla fosse elevada à capital oriental do Império. Este feito foi levado a cabo pelo então imperador

\footnotetext{
${ }^{1}$ POLÍBIO, Histórias, IV, 38, trad. De G. Godoy. In: HERRERA, H. \& MARÍN, J., "El império bizantino. Introducicón Histórica y Seleción de Documentos", Cuadernos Byzantion Nea Hellás - Série Byzantiní Istoría I, 1998, Centro de Estudos Gregos, Bizantinos e Neohelenicos “Fotios Malleros” da Universidade do Chile. (Disponível em www.geocities.com/milan313/MEDWEB.HTML, acesso em 20/09/2009).
} 
Constantino, o Grande (305 - 337) no ano de 330 d.C. Tal como fez Políbio, vários outros autores reconheceram que a geografia do Império Bizantino lhe trouxe inúmeras vantagens militares $\mathrm{e}$ mercantis. A meu ver, a localização de Bizâncio entre dois mundos Ocidente e Oriente - permitiu ao Império não somente manter boas relações políticas e comerciais com outros lugares, mas também assegurou que Bizâncio fosse herdeira da cultura clássica no mundo tardo-antigo e medieval, bem como fosse o principal centro intelectual e irradiador dessa cultura no Mediterrâneo.

De fato, os principais pilares do Império Bizantino demonstram o amálgama de duas importantes civilizações: a helênica e a romana cristã. $\mathrm{O}$ uso da língua grega sempre foi superior ao do latim entre os bizantinos, fato que ficou marcado quando por volta do século VI d.C. a língua latina entrou em decadência. A partir desta nova configuração, costuma-se dizer que o Império Bizantino, após o reinado de Justiniano (527-565 d.C.), adotou o grego como língua oficial ou que a língua dos romanos agora era o grego. Não somente a língua grega suplantou a latina, mas os costumes romanos deram lugar aos gregos. O Império Bizantino, que tentou por muitos anos restabelecer os domínios territoriais romanos e salvaguardar ao máximo suas tradições, abandonou seu ancestral latino e assumiu uma forma e um conteúdo cada vez mais helênicos². Assim, é graças

\footnotetext{
2 MARÍN, José. "El Imperio Griego de Bizancio. Una aproximación al mundo bizantino y su legado histórico". In: (Disponível em www.geocities.com/milan313/MEDWEB.HTML, acesso em 20/09/2009).
} 
a este predomínio da língua grega no Oriente Bizantino que uma comunicação mais intensa com as obras clássicas do passado helênico foi possível, bem como as leituras bizantinas dos pensadores cristãos tiveram um formato próprio, uma vez que o cristianismo muito bebeu do pensamento filosófico grego. Nesse sentido, procurarei entender aqui alguns meios que permitiram a grande erudição da sociedade bizantina.

A importância dada pelos bizantinos à educação foi um fator que teve, evidentemente, uma forte influência no caráter erudito de determinada parte desta civilização. Com efeito, "uma boa educação era o ideal de todo bizantino" ${ }^{3}$ e a apaideusia - falta de cultura mental - era considerada um infortúnio tremendo. Nesse sentido, para cultivar o gosto pelos estudos e para garantir que parte dos cidadãos fosse culta, a educação no Império Bizantino era bastante sistemática. Autores que trabalham com a questão da educação em Bizâncio costumam alertar para as inúmeras lacunas existentes na documentação sobre este assunto. Contudo, é possível ter uma boa noção dos métodos aplicados e dos conteúdos estudados pelas crianças e pelos jovens bizantinos. Estes métodos iniciavam-se com a educação dada pelas mães no ambiente familiar a partir da exposição oral de aventuras fantásticas da literatura e narrativas das Sagradas Escrituras. Devemos salientar que a educação já sob a tutela materna era direcionada majoritariamente aos filhos homens. Runciman

\footnotetext{
${ }^{3}$ RUNCIMAN, Steven. A Civilização Bizantina. Rio de Janeiro: Zahar Editores, 1961, p. 173.
} 
comenta que a educação das moças das classes mais abastadas era muito semelhante à de seus irmãos, porém as meninas recebiam instruções em casa por professores particulares, enquanto os meninos frequentavam locais próprios para o ensino. Os conteúdos dessa educação eram sem dúvida baseados nos ensinamentos gregos clássicos e nos cristãos.

Segundo Robert Browning, a educação fora do oikos familiar era dividida em três níveis, que remontam ao ensino na Grécia Clássica $^{4}$ o nível elementar, o da gramática e o da retórica. No primeiro nível, os alunos, com mais ou menos seis anos de idade, aprendiam os nomes e as formas das letras, as sílabas e as palavras mais curtas. Aprendiam também algumas fábulas que deveriam ser memorizadas, como as "Fábulas de Esopo". Este nível apresentava métodos pedagógicos simples, mas de extrema importância, pois ensinavam aos alunos as bases da escrita da língua grega.

Ao passarem para o nível da gramática, os estudantes aprendiam a ler e a compreender a literatura da Grécia Clássica, aprendiam também a morfologia dos substantivos e dos verbos e estudavam os vários dialetos em que a literatura estava escrita, bem como palavras de uso estritamente literário ${ }^{5}$. É importante lembrarmos o porquê da ênfase na língua grega escrita e seus diferentes usos. O grego falado pelos bizantinos era bastante distinto

4 BROWNING, Robert. "O Professor". In CAVALlO, Guglielmo. O Homem Bizantino. Lisboa: Editorial Presença, 1998, p. 95

${ }^{5}$ Idem, p. 96. 
do grego clássico, pois os intermitentes contatos com vocábulos latinos, árabes e armênios modificaram profundamente a estrutura da língua ${ }^{6}$. Nesse sentido, havia um grande abismo entre a língua popular e a língua dos homens cultos, esta inclusive foi considerada por alguns autores como uma "língua artificial". Não por acaso, portanto os bizantinos achavam difícil o estudo da poesia grega clássica. Sendo assim, atribuía-se fundamental importância ao estudo inicial da gramática, uma vez que esta embasava o prosseguimento intelectual dos alunos bizantinos. Para suprir a necessidade de tal aprendizado, o professor de gramática podia trabalhar com a Arte da Gramática (technê grammatikê), de Dionísio Trácio do século II a.C. e com os Cânones (Kanones), de Teodósio de Alexandria - c. 500 a.C.- que eram ambos tratados sobre morfologia e etimologia. Além da aprendizagem teórica, os professores davam ênfase em uma aprendizagem mais prática, que consistia em leituras de textos literários e que tinha por objetivo a memorização por parte dos estudantes. $O$ ensino baseado na oralidade e nas técnicas mnemônicas de retenção dos textos estudados era um dos pilares da educação bizantina, uma vez que a existência de cópias para os alunos dos tratados e dos livros trabalhados pelos professores era muito rara. Inicialmente, portanto, as obras homéricas como Ilíada e Odisseia deveriam embasar os conhecimentos memorizados pelos estudantes, seguidas por passagens da Bíblia.

${ }^{6}$ GIORDANI, Mario Curtis. História do Império Bizantino. Petrópolis: Vozes, 1997, p. 183. 
Como Bizâncio possuía uma cultura essencialmente oral, exigia-se que as pessoas públicas falassem bem. Para tanto, boa parte da educação consistia no aprendizado da retórica. Após passarem pelas aulas de gramática, os alunos bizantinos mergulhavam no estudo da oratória com aproximadamente quatorze anos. Nesta etapa, aprendia-se a "exprimir com elegância e persuasividade o pensamento" ". O sábio uso das palavras tinha, evidentemente, fins políticos, uma vez que os retores eram a principal forma de comunicação das províncias com o governo central, bem como de Constantinopla com outras localidades. As festas do Imperador, as cerimônias religiosas, civis e fúnebres também eram momentos públicos em que os retores deveriam saber utilizar as palavras de uma forma bela. Em um discurso de homenagem a seu mestre de retórica, Corício, no século VI, observava que "a qualidade de um retor é posta a prova por duas coisas: primeiro, pela capacidade de espantar o público com a sapiência e a beleza de suas palavras; segundo, pela iniciação dos jovens aos mistérios dos antigos" ${ }^{\prime}$. A oralidade tinha, pois uma função política fundamental na vida bizantina e o ensino básico deveria dar aos alunos as melhores técnicas da retórica. Os livros utilizados nesta etapa eram herdados da antiguidade-tardia e o principal deles foi o de Aftônio de Antioquia, do século IV d.C. coletânea de progymnasmata ou exercícios preliminares. O ensino da filosofia também se ministrava nesta etapa, apesar de constituir

\footnotetext{
${ }^{7}$ BROWNING, Robert. op. cit., p. 98.

${ }^{8}$ Idem, ibidem.
} 
matéria opcional. Contudo, o conhecimento filosófico era um sinal distintivo na sociedade bizantina, prova disso é a conservação dos manuscritos mais antigos de Platão, que sobreviveram devido às transcrições feitas em Bizâncio entre os séculos IX e X d.C. ${ }^{9}$

Apesar desta sistematização do ensino apresentada até aqui, não havia nenhum órgão que regulamentasse o que deveria ser estudado e o currículo seguido pelo professor. Browning aponta para o fato de que era a tradição que ditava as regras do ensino em Bizâncio, tradição esta proveniente da Grécia Antiga. Nesse sentido, nem o Estado nem a Igreja participavam ativamente no processo educacional. Devemos salientar ainda que parte dos alunos que começava o ensino básico não prosseguia até a Universidade. No entanto, Constantinopla era a cidade do Império que possuía a maior população estudantil, inclusive é interessante notar que havia muitos estudantes ocidentais na capital bizantina para aprender a língua grega clássica. Sem dúvida, a Universidade de Constantinopla foi a mais expressiva de Bizâncio, porém havia outros centros de estudos muito importantes como a Universidade de Beirute, expoente no ensino de Direito e a Universidade de Atenas, notória na atividade da Retórica.

Um grande exemplo da erudição dos bizantinos graças à dedicação aos estudos foi Miguel Pselo (1018-1078), humanista, filósofo neoplatônico, orador e historiador. $\mathrm{Na}$ realidade, é difícil limitar a atuação de Pselo em determinadas áreas do conhecimento,

\footnotetext{
${ }^{9}$ Idem, p. 102.
} 
uma vez que suas obras abrangem temas relacionados à política, à história, à filosofia, à teologia, à matemática, entre muitos outros. Em um relato presente na sua obra conhecida como Cronologia, Pselo se refere à orientação de seus estudos e conta que no início suas principais preocupações recaiam sobre o aprendizado da retórica e da filosofia: "Os meus esforços concentravam-se em dois objetivos: treinar a língua pela retórica, a fim de me tornar um bom orador e aperfeiçoar o espírito com um curso de filosofia". ${ }^{10}$

Nesta obra, Pselo cita os nomes dos principais filósofos estudados na época. Iniciava-se com Platão e Aristóteles e, posteriormente, passava-se ao estudo de Plotino, Porfídio, Proclo e Jâmblico, todos autores neoplatônicos dos séculos III, IV e V. Pselo narra que após esse momento voltou-se para as ciências naturais, "aspirando a conhecer os princípios fundamentais da filosofia através da matemática" ${ }^{11}$. $\mathrm{O}$ autor comenta ainda sobre o seu interesse pelo estudo da música e da astronomia e de "diversas artes subsidiárias". Pselo aponta para o fato de que após passar por estas matérias mais abrangentes, foi capaz de se lançar a estudos mais específicos. Essa brevíssima trajetória de um dos mais importantes eruditos bizantinos serve de exemplo para entendermos a sequência sistemática do estudo no Império. Para o cidadão atingir o nível superior de ensino era necessário que passasse por diversas áreas e que possuísse uma

${ }^{10}$ The Cronographia of Michael Psellus, trad. do grego por E.R.A. Sewter, New Haven, Yale University, 1953, “Constantine IX (1042 - 1055)”, pp. 127-130.

${ }^{11}$ Idem, Ibidem. 
boa instrução da língua, tanto oral como escrita, e um bom conhecimento filosófico.

Assim como o sistema educacional bizantino, a literatura também conservou as lembranças das produções gregas no período clássico. Enquanto no Ocidente tardo-antigo e medieval os mosteiros eram os principais centros irradiadores de cultura, no Império Bizantino a tradição de copiar obras clássicas perpassava por toda a sociedade de Bizâncio, dos monges aos seculares, sendo que os imperadores Teodósio II e João Cantacuzeno executaram inúmeras cópias. O trabalho de copistas, embora não fosse suficiente para atingir grande parte da população - lembremos que o ensino era essencialmente oral devido à falta de cópias para todos os estudantes -, era consideravelmente maior que em outros lugares nessa época e foi um trabalho fundamental para a manutenção e desenvolvimento da vida intelectual ${ }^{12}$. Mário Curtis Giordani, na obra História do Império Bizantino, nos apresenta algumas características gerais da literatura bizantina. Primeiramente, diz-se que faltava aos bizantinos uma espontaneidade criadora, ou seja, que havia uma limitação na sua expressão. Podemos entender esta constatação pelo fato já mencionado anteriormente da dualidade existente entre a língua da escrita e a língua da fala. Os bizantinos tinham grande dificuldade em se expressar de acordo com os cânones da língua grega e, por isso, essa falta de criatividade e a limitação da literatura, segundo Giordani, faziam com que sua produção fosse dividida em dois

\footnotetext{
${ }^{12}$ GIORDANI, op. cit..
} 
extremos: "a produção de hinos e obras de devoção místicas ou simples histórias e biografias" ${ }^{13}$.

Contudo, apesar da limitação apontada por Giordani, os bizantinos foram capazes de produzir tratados sobre os mais variados assuntos, como foi explicitado com o exemplo de Miguel Pselo. Também podemos perceber que a literatura bizantina, assim como diversos outros segmentos da sociedade, foi influenciada por diversas tradições. A que salta aos olhos é, evidentemente, a helênica, tendo os escritores de Bizâncio se esforçado ao máximo no aprendizado do grego clássico a fim de imitar os modelos literários antigos. Além da tradição grega, houve a influência das tradições cristã e oriental, esta pode ser constatada principalmente pela riqueza de imagens. A literatura de Bizâncio tinha, no entanto, um caráter essencialmente utilitário e prático, como podemos ver presente na obra do imperador Constantino VII Porfirogênito, De Administrando Império, redigida a seu filho sucessor do trono.

Constantino VII Porfirogênito fez parte da dinastia Macedônia (867 - 1059 d.C.), que se iniciou com Basílio I (867 - 886 d.C.) e terminou com Isaac I Comneno (1057 - 1059 d.C.). Os macedônios conseguiram uma forte organização interna permitindo grande expansão do Império, bem como neste período a estável situação do Ocidente favoreceu o crescimento do comércio bizantino ${ }^{14}$. Após a morte de Leão VI (886 - 912 d.C.), seu irmão

\footnotetext{
${ }^{13}$ Idem, p. 184.

${ }^{14}$ RUNCIMAN, op. cit., p. 37.
} 
Alexandre e seu filho Constantino VII passaram a governar o Império. Com a morte de Alexandre em 913, o governo passou para as mãos de Zoé Cabopsina, mãe de Constantino VII que governou como regente de 914 a 919. O reinado de Zoé foi, contudo, substituído pelo de Romano I em 919 após a invasão de Bizâncio pelos búlgaros. Romano I Lecapeno fez um bom governo e após sua queda em 944, apesar das tentativas de coroar um de seus filhos, Constantino VII Porfirogênito governou sozinho o Império Romano do Oriente de 945 a 959. Sob o governo deste basileu e de seu filho Romano II (959 - 963 d.C.) inúmeras conquistas orientais se efetivaram, como a recuperação de Creta e de Alepo.

Devido à conturbada situação de Constantino VII para atingir o poder, o basileu nascido da púrpura escreveu tratados a seu filho a fim de lhe auxiliar em seu reinado. De Administrando Imperio, Das Cerimonias e Dos Themas são as principais obras deixadas por Constantino VII Porfirogênito a Romano II, as quais são importantes relatos sobre a vida imperial e sobre as relações de poder em Bizâncio a partir do cotidiano de um imperador e de sua experiência.

De Administrando Imperio trata de questões relacionadas à política externa de Bizâncio com os povos vizinhos e com outras regiões de comércio. $\mathrm{Na}$ obra podemos perceber a importância dada por Constantino à educação daquele que deseja se tornar imperador. O basileu porfirogênito atenta seu filho para a necessidade de não ignorar seus conhecimentos e de governar com inteligência e 
prudência. Também salienta que o imperador é quem garante a segurança de todos e é aquele que guia seus súditos.

Hear now, my son, those things of which I think you should not be ignorant, and be wise that you may attain to government. For I maintain that while learning is a good thing for all the rest as well, who are subjects yet it is especially so for you, who are bound to take thought for the safety of all, and to steer and guide the laden ship of the world. ${ }^{15}$

Portanto, Constantino expressa nessas passagens a importância de que o governante seja uma pessoa instruída para efetivar seus deveres. Podemos perceber assim que a educação era fundamental para o basileu Constantino VII Porfirogênito, uma vez que ele próprio não poderia ter legado tais obras sem a sua erudição proveniente de uma boa e constante busca pelo conhecimento.

For I have not been studious to make display of fine writing or of an Atticizing style, swollen with the sublime and lofty, but rather have been eager by means of every-day and conversational narrative to teach you those things of which I think you should not be ignorant, and which may without difficulty provide that intelligence and prudence which are the fruit of long experience. ${ }^{16}$

15 CONSTANTINE VII PORPHYROGENITUS, De Administrando Imperio. Edição em inglês e grego por JENKINS, R.J.H. \& MORAVCSIK, G.Y., 1966, 2006 Dumbarton Oaks, Trustees for Harvard University, Washington, D. C. p. 49. ${ }^{16}$ Idem, Ibidem. 
Nesse tratado, Constantino demonstra um grande conhecimento sobre estratégias militares e sobre os povos vizinhos ao Império. Ao discorrer sobre os pecheneges, o basileu demonstra que efetivamente sabe do que está falando devido à sua experiência no trato com esse povo. Relata a importância de manter a paz com os pecheneges, pois o imperador os vê como uma nação poderosa. Ao manter boas relações com os pecheneges, os bizantinos também se encontrariam em paz com os russos e com os turcos, uma vez que estes últimos não eram capazes de atacar bizâncio sem o auxilio daqueles ("So long as the emperor of the Romans is at peace with the Pechenegs, neither Russians nor Turks can come upon the Roman dominions by force of arm." ${ }^{17}$ ). Através de constatações como esta, $D e$ Administrando Imperio é uma rica fonte para estudos sobre os contatos do Império Bizantino com outros povos. Contudo, o que desejo exemplificar com esta obra aqui é a importância atribuída pelo imperador Constantino VII Porfirogênito à erudição, sendo ele responsável ainda por um incremento das atividades intelectuais em Bizâncio. Além disso, a preocupação literária do basileu em produzir obras sobre seu legado aponta também uma preocupação histórica, no sentido de registrar seus feitos e deixá-los para a posteridade. ${ }^{18}$

A partir de um contato cada vez mais próximo do mundo bizantino com o Ocidente via Mediterrâneo, vários autores apontam

\footnotetext{
${ }^{17}$ Idem, p. 51.

${ }^{18}$ McCORNICK, Michael. “O Imperador”. In CAVALLO, Guglielmo. O Homem Bizantino. Lisboa: Editorial Presença, 1998, p. 230.
} 
para a grande influência exercida por Bizâncio sobre a cultura humanística do Renascimento. No período conhecido com antigüidade-tardia, ou seja, o momento caracterizado pela substituição dos valores antigos clássicos pelos feudais, o Ocidente não só se separou do Oriente greco-bizantino no âmbito político, mas também do conhecimento da língua grega e, consequentemente, do acesso direto à cultura grega clássica ${ }^{19}$. A partir de fins do século $\mathrm{XI}$, os contatos entre o Império Bizantino e o mundo ocidental se intensificaram e as Cruzadas abriram novos caminhos entre Oriente e Ocidente. Segundo Paul Oskar Kristeller, no período que compreende do século XI ao século XIV, surgiram traduções de textos gregos para a língua latina, o que permitiu uma primeira difusão e disponibilidade destes no mundo ocidental. Contudo, Kristeller salienta que estes primeiros contatos e influências foram bastante limitados, no sentido de não fazer florescer no Ocidente interesses mais aprofundados sobre o grego - interesses pela literatura, pela forma, pelos matizes do idioma, pelo estilo e pelo pensamento. Mas sem dúvida, este longo período de uma influência ainda tímida foi crucial para o posterior desenvolvimento dos estudos clássicos gregos na Europa ocidental.

O século XVI representa a grande mudança do estado dos estudos gregos no Ocidente. Anteriormente, as universidades europeias não haviam adotado o estudo do grego, sendo que muitos

${ }^{19}$ KRISTELLER, Paul Oskar. El pensamiento Renacentista y sus fuentes. Madrid: Fondo de Cultura Económica, 1993, p. 190. 
estudiosos, em busca de uma educação clássica grega, iam estudar em Constantinopla, como já mencionado neste trabalho. A partir da segunda metade do século XIV até o fim do XVI, pelo contrário, o ensino da língua e da cultura grega clássica estava estabelecido nas principais universidades do mundo ocidental, bem como nas bibliotecas podiam ser encontrados vários manuscritos clássicos.

Como já foi explicitado aqui, a educação bizantina era totalmente voltada para o estudo da língua grega clássica durante toda a Idade Média. Devido o fato de o Império Bizantino ter sido durante séculos o guardião da cultura helênica, os humanistas do Ocidente se voltavam para o Oriente atrás de textos a fim de desenvolverem os conhecimentos linguísticos e filológicos para leitura e compreensão destes materiais ${ }^{20}$. É interessante constatar que esse florescimento da cultura grega no mundo ocidental coincide com o declínio e a consequente queda definitiva do Império Bizantino. Kristeller aponta para o fato de que, apesar da decadência política de Bizâncio, este manteve sua inclinação aos estudos clássicos. Nesse sentido, com a crise que assolava o Império desde o século XII, muitos eruditos bizantinos emigraram para o Ocidente, em especial para a Península Itálica. Os sábios provenientes do Oriente traziam consigo inúmeros manuscritos gregos clássicos sobre os mais variados assuntos. Além disso, os humanistas italianos aprenderam com os mestres bizantinos o método filológico desenvolvido em Bizâncio para a melhor compreensão destes livros.

\footnotetext{
${ }^{20}$ Idem, p. 195.
} 
Sendo assim, podemos dizer que a presença bizantina em territórios ocidentais proporcionou não só um incremento dos estudos helênicos clássicos, como permitiu aos europeus se apropriarem das técnicas de aprendizado da língua grega, uma vez que a tradição pedagógica de ensino do grego veio das escolas bizantinas para as ocidentais juntamente com os homens cultos do Império ${ }^{21}$. Além da influência direta dos bizantinos na Europa ocidental, muitos dos humanistas que visitavam Constantinopla regressavam com uma bagagem intelectual e com muitos livros e manuscritos gregos, o que facilitava a difusão do conhecimento helênico no Ocidente.

Dessa forma, fica evidente a grande contribuição que toda a erudição preservada pelo Império Bizantino teve para o mundo ocidental. O estudo do grego clássico representou um dos pilares da cultura humanística do Renascimento italiano e, com isso, o desenvolvimento da filosofia neoplatônica e novas formas de pensar a literatura, a filosofia e a história foram possíveis. Assim sendo, apesar de não considerarmos a história como um movimento exclusivo de transposições de ideias, percebemos como a cultura da Grécia Clássica foi mantida e apropriada pelos bizantinos e como estes ampliaram seus domínios.

${ }^{21}$ Idem, p. 197. 


\section{Conclusão}

Neste artigo, procurei delimitar, ainda que de forma rápida, algumas condições culturais intrínsecas ao Império Bizantino e outras externas a ele que permitiram o desenvolvimento de uma sociedade cuja tradição apreciava a erudição. Percebi que o afastamento de Bizâncio com o Ocidente e vice-versa no mundo tardo-antigo e a consequente aproximação daqueles com a cultura helênica, fez com que os domínios de Constantinopla preservassem e perpassassem a cultura filosófica da Grécia Clássica. Apesar de não podermos falar em uma imitação dos valores clássicos gregos, os bizantinos evidentemente se apropriaram destes para embasar suas atividades intelectuais, no sentido de que juntamente com os ideais helênicos havia a rica justaposição de valores cristãos e latinos. Dessa forma, a erudição bizantina não pode ser vista como uma continuação da erudição grega, mas deve ser entendida, sobretudo, como um elemento que permitiu o encontro de várias referências e que teve fôlego suficiente pra lançar as bases para o nascimento de uma outra tradição intelectual no Ocidente - o humanismo renascentista.

\section{Bibliografia}

BROWNING, Robert. “O Professor”. In CAVALLO, Guglielmo. O Homem Bizantino. Lisboa: Editorial Presença, 1998. 
CONSTANTINE VII PORPHYROGENITUS, De Administrando Imperio. Edição em inglês e grego por JENKINS, R.J.H. \& MORAVCSIK, G.Y., 1966, 2006 Dumbarton Oaks, Trustees for Harvard University, Washington, D.C. p. 49.

GIORDANI, Mario Curtis. História do Império Bizantino. Petrópolis: Vozes, 1997.

KRISTELLER, Paul Oskar. El pensamiento Renacentista y sus fuentes. Madrid: Fondo de Cultura Económica, 1993.

MARÍN, José. El Imperio Griego de Bizancio. Una aproximación al mundo bizantino y su legado histórico. In: www.geocities.com/milan313/MEDWEB.HTML, (acesso em 20/09/2009).

McCORNICK, Michael. "O Imperador”. In CAVALLO, Guglielmo. O Homem Bizantino. Lisboa: Editorial Presença, 1998.

RUNCIMAN, Steven. A Civilização Bizantina. Rio de Janeiro: Zahar Editores, 1961.

VRYONIS, Speros. Bizâncio e Europa. Lisboa: Editorial Verbo, 1967. 